\title{
GHOSTS OF BRITAIN: A HAUNTOLOGICAl APPROACH TO THE 21ST-CENTURY FOLK HORROR REVIVAL
}

\author{
Alberto Andrés Calvo \\ Independent Scholar
}

\begin{abstract}
This article aims at investigating the American folk horror revival of the 2010s, focusing on texts such as Ari Aster's Midsommar (2019) or Robert Eggers's The VVitch (2015). This survey of the folk horror revival will inevitably lead us to the genre's past, particularly to the so-called Unholy Trinity, comprised by three films released in Great Britain during the late 1960s and early 1970s. This temporal and geographical dislocation will be situated against a larger background of cultural production, arguing that the appearance of the folk horror revival sheds some light on the debate on nostalgia and pastiche as the predominant artistic modes under late capitalism. The notion of hauntology, as explored by Jacques Derrida, Mark Fisher, or Katy Shaw, will be used throughout the essay in order to provide a firm theoretical ground on which this debate can take place.
\end{abstract}

Keywords: American folk horror, hauntology, nostalgia, Midsommar, The VVitch.

\section{INTRODUCTION}

The past decade has seen an increase in the number and popularity of folk horror films. The re-emergence of this horror sub-genre is particularly intriguing because it involves not only a temporal relocation but also a geographical one. The origins of the folk horror film can be traced back to the late 1960s and early 1970s in Britain with filmmakers such as Robin Hardy or Michael Reeves. However, many of the contemporary iterations of the genre come from across the Atlantic (see Robert Eggers's The VVitch [2015], Ari Aster's Midsommar [2019] or Malgorzata Szumowska's US-produced The Other Lamb [2019], among others). Unfortunately, and despite recent efforts by Adam Scovell, Andy Paciorek, and other scholars, folk horror 
remains largely under-theorised. Therefore, the first aim of this article is to contribute to the budding theorisation of folk horror.

Furthermore, this article also aims to investigate the folk horror revival through the lens of a wider debate on cultural production in late capitalism. The concept of hauntology is central to this debate. Derived from Jacques Derrida's late writings, hauntology can be understood as the study of cultural spectres, "a science of ghosts, a science of what returns. It destabilizes space as well as time" (Shaw 2). Hauntology has been seeping into discussions of art and nostalgia, first in popular music and gradually in film and literature as well. It ought to be stated that the relationship between folk horror and hauntology is entirely symbiotic. Hauntology is as useful to folk horror studies as folk horror is to hauntology studies. The emergence of both terms in academia is a recent and, perhaps more importantly, geographically bound phenomenon. Folk horror and hauntology studies have been so far tied almost exclusively to the British Isles. However, the recent appearance of an American form of folk horror forces us to re-evaluate this geographical connection. At this point, it bears asking several questions: how does this new American folk horror compare to its British counterpart from past and present? Can these new folk horror films be comfortably lumped with the rest of horror revivals and remakes being currently released? Are the films of Eggers and Aster as ripe for hauntological analysis as their transatlantic cousins?

\section{RunNing OUt Of PAST: ReMAKes And ReVIVAlS}

It is worth investigating this folk horror revival through the lens of a culture obsessed with its own past. Writing in 2011 about the music trends of the 2000s, Simon Reynolds argues that the first decade of the new millennium "has been about every other previous decade happening again all at once" (10). His book Retromania (2011) explores revivals and pastiche in popular music, following the steps of Marxist literary critics like Raymond Williams or Fredric Jameson. The latter's theories on the prevalence of the so-called "nostalgia mode" are echoed throughout Reynolds's work. Although their scope and target are different, both Jameson and Reynolds suggest that artistic production in late capitalism is under a state of arrested development, incapable of escaping its past precisely because the hegemonic social order has forced us to forget "how to think historically in the first place" (Jameson 1) and to altogether give up on progress, here understood as the establishment of a new social order. Reynolds calls the 2000 s the "Re" Decade, a span of time when the shadow of the past looms over cultural production more than at any other previous time, when revivals and pastiche reign supreme and occupy a privileged position in the music industry. Ten years after the publication of Reynolds's book, his words still ring painfully true. Though Reynolds writes about popular music, film is not exempt from this backward-looking craze. A cursory glance at the 50 highest 
grossing films of the 2010s reveals that almost all of them are sequels, remakes, spin-offs or some sort of combination of the three. ${ }^{1}$

Horror film has also been hit by a nostalgia wave. Although there might be an argument for horror as a genre that has always looked to its past and favoured film franchises, ${ }^{2}$ the truth is that the past few years have seen a proliferation of remakes (IT [2017], Child's Play [2019], A Nightmare on Elm Street [2010], sequels/reboots Halloween [2018] and Blair Witch [2016]), and purely nostalgia artifacts like Stranger Things (2016-ongoing) that take horror's historical tendency to looking back at its past to the next level. Now, folk horror has also been brought back to life. Are the new folk horror films part of this revivalist tendency? In order to answer this question, an expanded discussion on nostalgia by way of hauntology will be provided. However, it is worthwhile to take a slight detour and delve into the specifics of folk horror first.

\section{FOLK HORROR: A SHORT HISTORY}

Despite the genre's origins harking back to the late 60s in film and much earlier in literature, the emergence of "folk horror" as a critical term is a very recent phenomenon, ${ }^{3}$ particularly when studied in opposition to others like giallo, Gothic horror, or monster horror. In his book on folk horror, Adam Scovell argues that the term became popularised in 2010 when used by Mark Gatiss in his BBC documentary A History of Horror, and that it was coined as late as 2004 by filmmaker Piers Haggard. Haggard's The Blood on Satan's Claw (1971) is one third of what is popularly known as the "Unholy Trinity," completed by Michael Reeves's Witchfinder General (1968) and Robin Hardy's The Wicker Man (1973). These three films, all by British directors and released within five years of each other, are usually regarded as the three foundational texts of folk horror film. ${ }^{4}$ The three films express similar anxieties, arguably as a knee-jerk

\footnotetext{
${ }_{1}^{1}$ There are several sources for this, and the fact that the list of films only differs slightly according to each source makes the point stand even more strongly. The most reliable list is based on IMDb-owned website Box Office Mojo, which tracks box office revenue in an algorithmic way: https://www.imdb.com/list/ls026040906/

${ }^{2}$ After all, what are the first gothic and horror films but adaptations of previous literary material? David Pirie's book A Heritage of Horror (1973) offers an insightful look at the relationship between horror film and gothic literature, arguing that the British horror films are "in no way imitative of American and European models but derive in general from literary sources" (10).

${ }^{3}$ There is no mention of the term "folk horror" even in recent academic studies like Columbia University Press's European Nightmares: Horror Cinema in Europe Since 1945, published in 2012, or Wiley-Blackwell's A Companion to the Horror Film, published in 2014.

${ }^{4}$ In an attempt to avoid Anglocentrism, it ought to be stated that folk horror film existed before the Unholy Trinity. Horror scholars, Scovell among them, have made a commendable effort in recent years to reconcile the film history of countries like Finland with folk horror, citing Erik Blomberg's The White Reindeer (1952) as a prime example.
} 
reaction to the countercultural movements of the late 1960s. ${ }^{5}$ Rurality, anachronistic ways of living centred around tightknit societies, sexual liberation, cults: these are all thematic points of suture among the Unholy Trinity. However, each of the three films tackle these themes in a highly singular manner; they are simply too idiosyncratic and varied in tone for them to comprise a unified genre. The Wicker Man takes its cue from thrillers and even musicals, Witchfinder General appropriates a number of tropes from the Western, while the gory and racy The Blood on Satan's Claw borders on exploitation horror with its proneness to jump-scares and nudity.

It might be argued that the delayed emergence of folk horror as a critical category owes as much to the cult status of many of its main examples as it does to the inconsistent nature of the texts we are working with. It would be easy to cite irreconcilable differences and altogether renounce studying folk horror film as its own phenomenon. A perhaps bolder approach, which is the one that will be taken here, is to embrace these discrepancies and recognise them as an integral element of the genre. If a set of films as dissimilar as the Unholy Trinity is to be taken as the bedrock of folk horror film, it is only logical to oppose gatekeeping and accept texts that might deviate from the (admittedly unstable) standard set by these three films. This flirtation with genre is not exclusive to the Unholy Trinity; in fact, it is at the heart of the films of the British filmmaker Ben Wheatley, who, alongside his partner Amy Jump, has penned some of the most compelling folk horrors in recent times. Wheatley's 2011 film Kill List, for example, starts as a kitchen-sink drama, while 2013's A Field in England resembles a period comedy in its opening scenes only for it to gradually descend into horrific madness. Folk horror should be accepted as a critical category intrinsically destabilised by its intermingling with other genres. That is not to say, however, that any horror film with a passing relation to folklore or the rural merits being studied as folk horror. A certain degree of accuracy should still be pursued. Adam Scovell resists offering a singular definition of the genre, and, as has just been exposed, for good reasons. Perhaps the most satisfying definition of folk horror is one of the many offered by Scovell in the introduction of his book, where he defines it as "a work that uses folklore, either aesthetically or thematically, to imbue itself with a sense of the arcane for eerie, uncanny or horrific purposes" (17). This definition touches on many shared features of folk horror films, from the musical numbers in The Wicker Man or A Field in England to the folk legends behind the plots of The VVitch or Witchfinder General.

Providing a taxonomy of folk horror is a near-impossible task, but the above-mentioned definition may still be expanded on by offering a set of tropes shared by several folk horror

\footnotetext{
${ }^{5}$ Once again Adam Scovell is the scholar to turn to. His book Folk Horror includes interesting discussions on the Unholy Trinity as a reaction to the cultural background of their time, tying the films' concerns with hedonism to the counterculture's interest in drugs or sexual liberation, and pointing out that the three of them were all released "during what can be called the British counter-culture movement, almost acting as signposts for its tidal high-point of 1968 in Witchfinder and the dying, post-Manson embers of Wicker in 1973" (24).
} 
films. Part of the horrific aspects of these films is that the events usually take place in the outside and in broad daylight, thus subverting horror's predominant setting. The dark and closed spaces favoured by horror take the backseat; horrific events happen not only outside and during the day but also in communal settings. This is particularly true of these films' climaxes, which, as in most horror, pivot around death. The individualistic murder is here often replaced by human sacrifice. The true source of the horrific is not the murder itself but the fact that there is an audience observing and sometimes celebrating it. Folk horror tends to insert the viewer into these diegetic audiences, in what is effectively yet another turn on horror's usual strategy of affect, here understood by following Xavier Aldana Reyes's description of it as the way in which "our bodies may be moved by those we see on the screen" (3). In horror, we experience fear and dread vicariously by reacting to the horrific events happening on-screen. Folk horror adds another layer by which we are also horrified by the reaction (or lack thereof) of an audience that is more often than not complicit in this human sacrifice. The powerful last acts of The Wicker Man and Midsommar serve as perfect examples for this point, as it might be argued that both films force their viewers to be complicit with the diegetic audience by presenting the sacrificed outsiders in opposition to the more enticing and adventurous natives. In the former, the painfully dull and sanctimonious Sergeant Howie stands in stark contrast to the sexually liberated natives of Summerisle, while Midsommar spends a good portion of its running time depicting Christian as intellectually dishonest and emotionally abusive.

Following on the traits listed above, it might be argued that these films engage with the occult rather than the supernatural: it is also worth noting that, when the supernatural does emerge, it is usually after the characters have been exposed to drugs and other perceptionaltering substances (A Field in England, Midsommar), or by tying the supernatural to religious tradition (The VVitch or The Blood in Satan's Claw). These films are all marked by a necessarily isolating landscape - the banishment of the Puritan family in The VVitch, Sergeant Howie's inability to escape Summerisle in The Wicker Man, or the constant references to phones not working properly in Midsommar -, which can sometimes be outright oppressive and claustrophobic however open it might appear (A Field in England). Furthermore, precarious living conditions caused by the land itself are usually the triggers behind the plots (see the failing crops in The Wicker Man or The VVitch, or the quite literal image of the evil emerging from the ground in The Blood on Satan's Claw).

In some of these films, folk horror works by contrasting the dominant cultural practices of Westerners with those of the Other. It usually involves a set of characters that are transposed to an unfamiliar setting, at odds with their culture and religion. Think, for example, of the anthropology students - one of them conspicuously called Christian-visiting a Swedish cult in Midsommar, or the banishment to the woods of the Puritan family in The VVitch. Scovell identifies these settings with "skewed belief systems" (30) as places where progress has stopped. The notion of progress stopping, particularly when referring to areas outside the 
influence of Western civilisation, is not without its problems. It would perhaps be more accurate to say that progress has taken an unexpected turn through a return of the occult. In any case, the introduction of progress grants folk horror a political and temporal dimension that eases our transition to hauntology.

\section{HAUNTOLOGY}

A play on words between "haunt" and "ontology," the term first appeared in Jacques Derrida's essay "Spectres of Marx," published in 1993 as an effort to reconcile deconstruction with Marxism in the wake of the fall of communism. Opposing Francis Fukiyama's post-ideological defence of liberal democracy as the rightful ending point of history, Derrida ponders on the ghosts of Marxism that kept haunting world politics in the late 20th century. Derrida builds on spectrality as an unavoidable non-presence: just like repressed and deferred meanings come back to haunt the text, so does Marxism endlessly return to haunt the hegemonic social system: "No disavowal has managed to rid itself of all of Marx's ghosts. Haunting belongs to the structure of every hegemony" (34).

Though not de-politised by any stretch, "hauntology" was adopted as a music genre descriptor in the mid-2000s by critics like Mark Fisher or Simon Reynolds, who expressed a concern about the omnipresence of revivals and pastiche in popular music in the opening decade of the 21st century. Fisher, who became one of hauntology's most eloquent theorists and championed the term's inclusion in academic cultural studies, speaks of hauntology as a reaction to life under neoliberalism, where every single aspect of life is subject to market relations and late capitalist logic. Hauntology evokes a lament for the stifling of imagination provoked by these material conditions, effectively wondering out loud whether we have lost the capacity to imagine a different future. The future, Fisher argues, "is always experienced as a haunting: as a virtuality that already impinges on the present, conditioning expectations and motivating cultural production" (16). If there is no future in sight, Fisher argues, then cultural production will remain stuck in an inescapable loop of repetition and pastiche.

Fisher and Reynolds saw hauntology as an apt descriptor for artists keen on recovering lost futures whose implications went beyond aesthetics. ${ }^{6}$ They used the term in order to describe the works of a number of mostly British electronic music acts that focus on the materiality of recording technology through noises like vinyl crackle or through physical deterioration of the material source of sound. Hauntological art foregrounds the interplay between technology and the past, exploring themes of longing and decay through sheer materiality. In

\footnotetext{
${ }^{6}$ The politics of hauntology reflects a longing for a social order progressively wound down with the establishment of neoliberalism. However, it would be an error to say that hauntology is a naïvely optimistic look back at the past. What is being longed for is not the past social order but the futures that said social order allowed us to dream up, the fact that it allowed "the capacity to conceive of a world radically different from the one in which we currently live" (Fisher 16).
} 
music, that is best exemplified by the omnipresent vinyl crackle and sampling of records of bygone eras in Burial's Untrue (2007), or by William Basinski's The Disintegration Loops (20023 ), a series of four albums consisting of pieces of music that are being played on loop on a tape. The tape's gradual deterioration transforms the recording itself to the point of no recognition. Another prime example is The Caretaker's Everywhere at the End of Time. Released in parts throughout the 2010s, this six-stage album mirrors the effects of dementia by progressively distorting pre-war ballroom vinyl samples until they become a ghost of their former selves, with a handful of leitmotifs appearing several times throughout the six-hour album under different guises. Hauntology was initially posited in opposition to nostalgia. If nostalgia is the straight, sometimes uncritical introduction of past tropes tied up to a bygone social order, hauntology experiments with these tropes by granting them a ghostly character. However, the distinction between the two terms is not as clear-cut as many of the theorisers of hauntology wished it was. Fisher's short essay, "No Future 2012" (2020), is a good example of how easy it is for hauntology to become tangled up with nostalgia. Building his argument off Fredric Jameson's seminal text on postmodern pastiche, Fisher argues that

The preoccupation with the past in hauntological music could easily be construed as "nostalgic." But it is the very foregrounding of temporality that makes hauntology differ from the typical products of the nostalgia mode, which bracket out history altogether in order to present themselves as new (716).

The counterargument to Fisher's point would be that products of the nostalgia mode can (and do) also foreground temporality, often through self-referentiality and self-awareness of their status as a recycled cultural artifact. What ultimately defines hauntology is not the foregrounding of temporality itself but the ways in which this foregrounding takes place through formal devices concerned with the materiality of the work of art. A nostalgic work might foreground temporality through self-awareness and meta commentary. ${ }^{7}$ However, that does not necessarily make it hauntological. By venturing beyond self-awareness and meta discourse, hauntology thematises the dialogue between past and present through formal techniques that highlight the temporal incongruities that Fisher, taking up on Derrida's conception of time as "out of joint" (34) aptly names "the time-wound" (716). Hauntological art opens and navigates this time-wound, establishing a dialogue between past and present. Insisting on hauntology's dimension outside aesthetics, Fisher argues that the first hauntological records he encountered "sounded 'ghostly,' certainly, but the spectrality was not a mere question of atmospherics" (16). Fisher's point is evident: the spectrality of hauntological art goes beyond an aesthetic eeriness. Nevertheless, those ghostly sounds (or, in the case of film, analogous formal devices

\footnotetext{
7 There are plenty of examples of this in horror film, particularly from the 90s onwards, like Wes Craven's postmodern slasher Scream (1996), whose investment in self-awareness grows with every sequel. More recent examples include Drew Goddard's The Cabin in The Woods (2011) or the horror-influenced comedy What We Do in The Shadows (2014).
} 
that achieve the same effect) should be pushed to the fore if one is to differentiate between hauntology and nostalgia.

In music, these ghostly atmospherics are achieved through samples that, as Jamie Sexton puts in his valuable re-negotiation between hauntology and nostalgia, "can be transformed into more eerie sonic markers when treated with effects such as reverberation" (564). Sexton's introduction of the word "eerie" is not casual, and it opens up yet another avenue of communication between horror and hauntology. "Eerie" is, after all, a term commonly used to refer to unsettling art which involves questions of spectrality and presence. In his book The Weird and The Eerie, Fisher argues that the eerie "occurs either when there is something present where there should be nothing, or if there is nothing present when there should be something" (61). Fisher's notion of eeriness fits nicely into the formal thematization of the time-wound in hauntological art. Formal devices like vinyl crackle or the degradation of physical tape exemplify that which is present where there should be nothing-we don't expect recorded music to incorporate sounds sourced from the act of recording itself.

As shown above, the link between hauntology and horror is not one that needs to be artificially drawn up. Film, particularly horror, has always been central to an understanding of hauntology. Note how, for instance, the hauntological music label Ghost Box draws samples from British horror films and TV from the late 1960s and early 1970s, from the work of Nigel Kneale to the Unholy Trinity. ${ }^{8}$ The dialogue between hauntological music and film is at its healthiest and more open. The anxieties expressed by hauntological musicians are now being transmitted by horror filmmakers, who are manifesting them through formal devices (as in Ben Wheatley's A Field in England, which will be expanded on below) or through a thematic exploration of the time-wound, as in the work of the Americans Aaron Moorhead and Justin Benson, who specialise in science fiction-horror hybrids. As hinted at by its title, the latter's 2017 film The Endless involves a cult whose members are trapped for eternity in their own particular time loops. Almost working as a remark on the conflict between self-aware nostalgia and hauntology, The Endless presents a scenario where the terror stems precisely from self-awareness. Some cult members are well aware of their time-prison and try to escape it through violent death only to reappear at the exact same time and place. In what can be read as a commentary on nostalgia and the futility of metafictional devices to open valuable dialogue with the past, The Endless presents a situation where self-awareness never allows the cult members to escape the time-loops; on the contrary, it only sinks them deeper into despair.

An additional point in common between hauntology and folk horror is that they are disciplines intrinsically attached to the preservation of an alternative heritage. Both are interested in left-field forms of popular (we might even venture to call them "folk") heritage, as Jamie Sexton argues: "Ghost Box and its affiliates can be partly related to this surge of interest in marginal national history, in preserving a form of alternative heritage" (572). While not

${ }^{8}$ See Sexton: "The Wicker Man and Blood on Satan's Claw have both been cited as influential by Ghost Box (and have also had their soundtracks released by Trunk Records)" (574). 
hegemonic, this heritage is still tightly bound with notions of nationality. At least in its musical manifestations, hauntology has mostly been regarded as a British discipline. The association between hauntology and Britain is surely aided by the fact that most hauntology scholars are British (see the aforementioned Fisher and Reynolds, or more recent academics like Katy Shaw or Adam Scovell), a trait shared by the cultural artifacts these writers tend to prioritise.

Folk horror is one of these prioritised artefacts. Again, the recurrent examples are British, whether they come from the past (The Unholy Trinity, Nigel Kneale's TV dramas and films) or from the present (Ben Wheatley's Kill List and A Field in England). Fisher argues that hauntology's Britishness is not accidental but consequential of a longing caused by "the expectations raised by a public service broadcasting system and a popular culture that could be challenging and experimental" (18). However, the past few years have seen an increase in the number - and, perhaps more strikingly, in popularity - of American folk horror films. Can we build a bridge between the new American iteration of the subgenre and hauntology? Do these films engage with their pasts through hauntological devices?

\section{FolK HORROR REVIVAL: HAUNTOLOGICAL OR NOSTALgic?}

Music is one of the keys to answer this question. Robert Eggers's The VVitch (2015) serves as a particularly useful example. Eggers's brief to composer Mark Korven was to come up with a minimalistic and amelodic score that eschewed all electronics. ${ }^{9}$ As a result, the film's soundtrack is comprised of traditional hymns like "Alas! And Did my Savior Bleed," - which initially seem to be grounding The VVitch firmly as a period film - and a number of terrifying and atonal folk ambient pieces. The key word in folk ambient is "folk": Korven's score bears a number of similarities with electronic ambient music, most notably the omnipresence of drones, but it achieves this through the use of obscure traditional instruments like the nyckelharpa instead of through any digital sources. This generates an overlapping of timelines that destabilises The VVitch's status as a period film and opens up the time-wound. Due to the use of left-field, drone-producing instruments, the score is ultimately more reminiscent of the electronic-laden ambient records of Brian Eno and Grouper than of any folk music made with analogue instruments. The score's spectral quality is indebted to the eeriness of the music itself as much as it is to the sheer materiality of the instruments used, allowing for the encounter between various temporalities - and, given that the film's characters are English settlers, geographies - to take place.

David Church notes in his book on horror in the 2010s that composing The VVitch's score pushed Korven to commission the creation of a new instrument nicknamed "The Apprehension Engine." As Church points out, the instrument's sound is more terrifying "because their source seems more obscure, less readily pinned down via common referents in the listener's

\footnotetext{
9 See Mark Korven's interview with Fact Magazine: https://www.factmag.com/2016/02/16/streamthewitch-score-mark-koven-interview/
} 
mind" (1). The absence of a common referent allows us to describe this sound as spectral. Korven's commissioning of The Apprehension Engine is a fascinating example of the conversation between material polar opposites opened by hauntology, whereby an analogue instrument is chasing the spectrality of the digital. Although The VVitch predates the commissioning of The Apprehension Engine, its score features the same sort of spectral sounds which this new instrument emits. The VVitch recycles aesthetic settings and plot points from the past: there are innumerable examples of horror films set in the woods, and Eggers's film's portrayal of a young woman whose Christianity is put into question is not particularly innovative for the horror genre either. However, the film's engagement with the past through the spectral nature of its score rescues it from the nostalgia mode; it is eminently hauntological in its exploration of the time-wound via an unresolved tug-of-war between analogue and digital.

Ben Wheatley's A Field in England, scored by his frequent collaborator Jim Williams, offers a different approach to the time-wound. What is at work in the score for Wheatley's film is not dissimilar to the hauntological experiments of Basinski and The Caretaker. The film's main theme is "Baloo My Boy," a popular Scottish song from the Early Modern period. The tune's first appearance in the film is diegetic, as it is sung by one of the protagonists. As in The VVitch, the introduction of a centuries-old folk song fences A Field in England as a period film. However, as the narrative advances and the deserters succumb to the mind-altering effects of the mushrooms they have consumed, the score turns more synth-based and experimental. By the film's ending, "Baloo My Boy" appears not sung by a character but as a heavily distorted version that is just reminiscent of the song's original form. The song's degradation through electronic means is effectively a way to tear a hole into the film's historical fabric, opening up the time-wound and shattering the barrier between diegetic and non-diegetic. This should be regarded as a hauntological trope: dis-synchronicity and anachronisms are brought about by formal devices concerned with the materiality of music, mirroring Katy Shaw's argument on spectrality and temporality: "the encounter with the spectre marks the point at which multiple temporalities meet and cross" (15).

As Wheatley and Williams explain in an interview in the Blu-Ray edition of the film, the shift from fairly traditional period music (from "Baloo My Boy" to the thundering drums as harbinger of war in the film's opening scene) to psychedelic electronic mirrors the deserters' changing perception of their physical surroundings once the effects of the mushrooms have finally kicked in. One might even go further and claim that it also mirrors the change of tone that occurs in the film's last act, where the comedic elements are brushed aside in favour of an engulfing sense of claustrophobic dread. The juxtaposition of traditional folk and electronic music is reminiscent of the hauntological sonic experiments of the Ghost Box label and others: like Julian House and Jin Jupp note, the artists working for the BBC Radio Workshop, from which hauntological music sources a series of samples, had "studied medieval music" (Sexton 577) and even made an electronic folk album. 
This juxtaposition also plays into the analogue/digital polarity explored in A Field in England. The psychedelic last act of the film is completely reliant on visual effects that could only be achieved through digital technology. The blurring of the boundaries between analogue and digital, past and contemporary, heightens the film's hauntological affect. And, in this case, such blurring is not only restricted to music. In his paper on A Field in England, Joel McKim mounts a strong argument for the film's digital anachronism as the main indicator of its unsettling effect. McKim argues that the film's digital colour grading brings about "a complicated set of overlapping historical temporalities - the Civil War setting of the film viewed through the prism of a 1960s television aesthetic created via a contemporary digital technique" (48). As with the score in The VVitch, the time-wound is brought about by formal techniques whose concern with materiality situate the film at a temporal crossroads. Wheatley's exploration of the time-wound digs even deeper than Eggers's as it is not only limited to music. It might also be argued that it reinforces Fisher's argument about hauntology's inherent Britishness. One of the main exponents of the 1960s television aesthetic that McKim refers to is Nigel Kneale, whose sci-fi and horror work for the BBC in the 1950s and 1960s maintains its cult status in Britain (it has often been sampled by British hauntological musicians) but remains largely unexplored elsewhere.

So far, this essay's efforts have been placed on contemporary folk horror films that extend the genre's long-standing affair with hauntology. That is not the case of the work of Ari Aster, whose films Hereditary and Midsommar are among the most commercially successful and critically acclaimed horror titles of recent years. Although Hereditary bears a folk horror influence, the focus here will be on Midsommar, a film that openly engages with the history of the subgenre. Again, music is a convenient starting point. The score to Midsommar, composed by the electronic artist The Haxan Cloak, presents a neat distinction between the folk-oriented orchestral pieces ("Fire Temple," "Maypole") and the asphyxiating, over-pitched string pieces that, recycling a well-trodden horror trope, are reserved for the most shocking and horrifying scenes. The merger of digital and analogue present in A Field in England or The VVitch is nowhere to be found here. The score does include electronic elements, but they are not on an equal footing with its folk numbers, nor is there any amalgamation between the two. Unlike Wheatley and Eggers, Aster is not interested in the hauntological exploration of the timewound through music. In fact, it could be argued that he is not interested in exploring the time-wound at all. Although Midsommar takes place in the present day, its setting in a remote rural commune in Sweden suggests both a geographical and temporal dislocation. However, said dislocation is explored only through certain aesthetics features (e.g. the score's Nordic folk influence or the film's costume design), not through formal devices related to the very materiality of the film as in Eggers's or Wheatley's films. In Aster, the barrier between different temporalities and geographies remains firmly in place because there is no attempt to bring it down. 
Returning to Jameson's definition of nostalgia as ahistorical revisionism is particularly useful when discussing Midsommar in these terms. As previously argued, historical explorations of material conditions are central to past and present folk horror titles. These precarious living conditions, always tightly bound to the land itself, are the driving forces behind the plots of The Wicker Man, where a sacrifice is needed after a season of failing crops, of The Vitch, in which hunger turns the family against each other, and even in titles set in the present day such as Wheatley's Kill List, where the economic recession of the late 2000s forces two former British soldiers to accept a job offered by a shady cult. These material concerns are all but absent in Midsommar other than in the form of a passing reference to climate change made by one of the cult leaders ("and what poetry that it's now the hottest and brightest summer on record") that is never picked up on again. Following Jameson, Aster's film could be regarded as nostalgic in that it is not interested in thinking in historical or material terms. Due to this refusal, Midsommar's intense climax differs from the one in A Field in England. Both films make use of similar technical wonders during their drug-fuelled last acts, doing a commendable job of evoking horrific disorientation through dizzy camera work and nightmarish music. The difference is that the formal blurring of temporalities grants Wheatley's film a historical dimension. By presenting these aesthetic components in dialogue with the past, A Field in England interrogates notions of decay and historical progress, whereas Midsommar's ending remains impressive merely aesthetically. This contrast brings back to mind Fisher's and Reynold's defence of hauntology against nostalgia. Both are representations of backward glances, but hauntology ventures beyond aesthetics and encourages historical and political discussions of art.

Because of its ahistoricism, Midsommar's relationship to folk horror works mostly as an aesthetic scaffold on which its familiar horrors are built. Unlike the folk horrors previously mentioned, Aster's film is not concerned with historical explorations of time and place but with the expression of affect. Like Ari Aster's 2017 debut Hereditary, Midsommar wears its scares on its sleeve: the film starts with a shocking image, as the protagonist's sister kills her parents and commits suicide. It is not so much the deaths themselves that cause the shock but Aster's insistence on showing us the pain they inflict on Dani, the protagonist. Aster continues folk horror's long-standing history of incorporating elements from other genres. The expression of grief by female characters is a recurrent trait in his work, which finds a middle ground between folk horror and exploitative, torture porn ${ }^{10}$ films like Hostel or Saw. The difference in that, in Aster's case, the torture is not only physical but also emotional. Aster's focus on pain not caused by physical threat but by emotional distress offers a twist on folk horror's strategy

\footnotetext{
${ }^{10}$ Like folk horror, torture porn is another heavily contested subgenre. For an in-depth discussion of torture porn, see Steve Jones's book Torture Porn: Popular Horror after Saw (2013). The term is here to refer to a number of horror films released in the 21st century that are "primarily based around protagonists being imprisoned in confined spaces and subjected to physical and/or psychological suffering." (Jones 13).
} 
of affect through the appearance of diegetic audiences complicit with the horrific events. Midsommar presents two of these complicit diegetic audiences. The most obvious one is the Swedish dish cult, whose members celebrate the brutal sacrifices taking place during the festival. However, there is also a complicit audience to Dani's grief from the very first scenes, as Christian and his friends remain apathetic to her tragedy, if not dismissive. Aster's incorporation of torture porn tropes into folk horror grants his films a sense of reckoning with grief and fear that goes beyond life-threatening bodily agony.

Like with The VVitch or A Field in England, the spectre of familiarity haunts Midsommar. ${ }^{11}$ Unlike the two previously mentioned films, however, Midsommar only engages with these spectres aesthetically, through the sort of ahistorical aping decried by Fredric Jameson as "the wearing of a linguistic mask, speech in a dead language" (17). In this sense, Midsommar is a fitting example of art born out of the nostalgia mode favoured in late capitalism. Whereas Eggers's and Wheatley's films engage with the past through symbiotic dialogue, Aster simply stares at it from afar, letting past and present stand as clearly separate entities. Although its exploration of grief is novel for folk horror, Midsommar can ultimately be seen as folk horror pastiche: it does not engage with its past ghosts through formal conversation but is simply satisfied with wearing their mask.

\section{CONCLUSIONS}

The contrasting ways in which the folk horror revival films tackle their relationship with their past signals the opening of two diverging paths for folk horror. In the first one, traversed by The VVitch or A Field in England, the films engage in symbiotic dialogue with their ghosts through formal devices, linking their concern with temporality to the material fabric that shape them. The second path, best exemplified by Midsommar, involves a willing refusal to start a conversation with these ghosts. As has been demonstrated, connecting the folk horror revival to the wider conversation on late capitalist cultural production produces illuminating results on both counts, going beyond making value judgement on the aesthetic merits of these films. We can therefore conclude by stating that, in its myriad ways, the folk horror revival is paradigmatic of current modes of cultural logic.

A solid argument has been made for hauntology as an effective theoretical framework to explore the new American folk horror, particularly when placed in opposition to its British counterpart. There are good reasons why hauntology remains mostly a field of study concerned with British films and music, and as previously explained, the magnitude of formal explorations of time and place is greater in the films of Ben Wheatley than in Aster's, or even Eggers's. However, an effort should be made to free hauntology from its constraining

\footnotetext{
${ }^{11}$ This familiarity is amplified by the film's paratext, perhaps more tellingly with the casting of William Jackson Harper as an out-of-place intellectual in what is effectively a reprise of the actor's role in the popular Netflix sitcom The Good Place (2016-2020).
} 
Britishness, as its usefulness as a critical tool to inspect art's relationship with its past overcomes all geographical bindings. Hauntology's concern with alternative heritage could open the door to an expansion of American folk horror film beyond the current revival, helping to draw up a genealogy of the subgenre that includes texts not previously studied under this light.

\section{WORKS CITED}

Aldana Reyes, Xavier. Horror Film and Affect: Towards a Corporeal Model of Viewership. Routledge, 2016.

Aster, Ari, director. Midsommar. A24, 2019

-. Hereditary. A24, 2017.

Basinski, William, musician. The Disintegration Loops. Musex International, 2002-2003

Bayer, Samuel, director. A Nightmare on Elm Street. New Line Cinema, 2010

Benson, Justin, and Aaron Moorhead, directors. The Endless. Snowfort Pictures, 2017

Bowe, Miles. "The Witch Composer on Making the Most Nightmarish Horror Score You'll Hear This Year." Fact, https://www.factmag.com/2016/02/16/stream-the-witch-score-mark-koven-interview/. Accessed 3 March 2021.

Burial, musician. Untrue. Hyperdub, 2007

Church, David. Post-Horror: Art, Genre, and Cultural Elevation. Edinburgh University Press, 2021.

Clement, Jermaine, and Taika Waititi. What We Do in The Shadows. Paramount Pictures, 2014.

Craven, Wes, director. Scream. Dimension Films, 2016

Derrida, Jacques. Specters of Marx: The State of the Debt, the Work of Mourning and the New International. Routledge, 2006.

Duffer, Matt, and Ross Duffer. Stranger Things. Netflix, 2016.

Eggers, Robert, director. The VVitch: A New England Folktale. A24, 2015

Fisher, Mark. The Weird and the Eerie. Repeater Books, 2017.

-. “What Is Hauntology?” Film Quarterly, vol. 66, no. 1, 2012, pp. 16-24.

-. Ghosts of My Life: Writings on Depression, Hauntology, and Lost Futures. Zero Books, 2014.

-. "No Future 2012". K-Punk: The Collected and Unpublished Writings of Mark Fisher. Repeater Books, 2020.

Goddard, Drew, director. The Cabin in the Woods. Lionsgate, 2011.

Gordon Green, David, director. Halloween. Blumhouse Productions, 2018. 
Haggard, Piers, director. The Blood on Satan's Claw. Tigon British Film Productions, 1971.

Hardy, Robin, director. The Wicker Man. British Lion Films, 1973

IMDb. 2021. The 50 Highest Grossing Movies of the 2010s (Worldwide) - $I M D b$, https://www.imdb.com/list/ls026040906/. Accessed 5 March 2021.

Jameson, Fredric. Postmodernism, or, the Cultural Logic of Late Capitalism. Verso Books, 2009.

Jones, Steve. Torture Porn: Popular Horror After Saw. Palgrave Macmillan, 2013.

Klevberg, Lars, director. Child's Play. Orion Pictures, 2019.

McKim, Joel. "The Digital Anachronisms of Ben Wheatley's A Field in England." Critical Quarterly, vol. 58, no. 1, 2016, pp. 46-51.

Muschietti, Andy, director. IT. New Line Cinema. 2017.

Pirie, David. A Heritage of Horror: The English Gothic Cinema 1946-1972. Equinox Books, 1973.

Reeves, Michael, director. Witchfinder General, 1971.

Reynolds, Simon. Retromania: Pop Culture's Addiction to Its Own Past. Faber \& Faber, 2011.

Scovell, Adam. Folk Horror: Hours Dreadful and Things Strange. Auteur Publishing, Leighton, 2017.

Sexton, Jamie. “Weird Britain in Exile: Ghost Box, Hauntology, and Alternative Heritage.” Popular Music and Society, vol. 35, no. 4, 2012, pp. 561-584.

Shaw, Katy. Hauntology: The Presence of the Past in Twenty-First Century English Literature. Palgrave Macmillan, 2018.

The Caretaker, musician. Everywhere at The End of Time. History Always Favours the Winners, 20162019.

Wheatley, Ben, director. A Field in England. Rook Films Limited, 2013.

-, and Jim Williams. A Field in England: An Interview. Rook Films Limited, 2013.

Wingard, Adam, director. Blair Witch. Lionsgate, 2010. 